\title{
A model for the permanent deformation behavior of the unbound layers of pavements
}

\author{
M.S. Rahman \\ Pavement Technology, Swedish National Road and Transport Research Institute (VTI), Linköping, \\ Sweden \\ S. Erlingsson \\ Pavement Technology, Swedish National Road and Transport Research Institute (VTI), Linköping, \\ Sweden \\ Faculty of Civil and Environmental Engineering, University of Iceland, Reykjavik, Iceland \\ A. Ahmed \& Y. Dinegdae \\ Pavement Technology, Swedish National Road and Transport Research Institute (VTI), Linköping, \\ Sweden
}

\begin{abstract}
This article presents a model for the permanent deformation (PD) behavior of unbound granular materials (UGMs) used in the base and subbase layers of pavement structures. The model was developed based on multistage (MS) repeated load triaxial (RLT) testing. This is essentially a modified version of a previously developed model to better suit to field conditions in a simple and effective manner. The model was calibrated for eight commonly used UGMs using MSRLT tests with a range of moisture contents. For validation, the calibrated models were used to predict the PD behavior of three of the UGMs in MSRLT tests with stress levels and moisture contents different from those used during the calibrations. This model showed better quality of fit when compared with another widely used PD model. The model was further tested successfully for field conditions by capturing the PD behavior of an instrumented pavement test section in a controlled environment using a heavy vehicle simulator (HVS) based accelerated pavement testing (APT). Inputs for calibrating the model were based on the readings from the instrumentations. The parameters of the model were adjusted to match the measured data with the predictions. Based on these results for various design conditions, some ranges of values of the material parameters of the model were suggested.
\end{abstract}

Keywords: Unbound granular materials, permanent deformation, model, triaxial test, moisture

\section{INTRODUCTION}

Gradual accumulation of permanent deformation (PD) in unbound granular materials (UGMs) used in the base and sub-base layers of flexible pavements may lead to rutting and eventual failure of the structure (Hornych and El Abd, 2004). Mechanistic-empirical (ME) design of pavements requires predicting the deformation behavior of the UGMs used in different layers, for the expected traffic load and environmental conditions, using constitutive models (Ramos et al., 2020). The aim is to control rutting and to implement it in pavement 
management systems and in life cycle cost analysis (Di Graziano et al., 2020). Ideally, the constitutive models should be able to reliably predict the deformation behavior of the materials considering the major influencing factors on the behavior. However, this is relatively difficult to achieve because of the complex and nonlinear behavior of the materials (Gidel et al., 2001, Hornych and El Abd, 2004).

Several of the PD models for UGMs predict the accumulation of PD with the number of load cycles by combining the influence of stress levels (Lekarp, 1999, Gidel et al., 2001, Korkiala-Tanttu, 2005). In a study by Rahman and Erlingsson (2014), the models proposed by Gidel et al. (2001) and Korkiala-Tanttu (2005) showed satisfactory performance in MultiStage (MS) Repeated-Load Triaxial (RLT) tests. However, these models relate the amount of permanent strain to the shear strength properties of the material. The shear strength parameters are determined using static failure triaxial (SFT) tests. At least three SFT tests are required for each UGM to reliably obtain these parameters. Then the RLT test is used to evaluate the rest of the parameters of the models. This is quite time consuming and expensive. Again, these models do not explicitly include the important factors, such as moisture content $(w)$, particle size distribution (PSD) and the degree of compaction that affect the PD behavior. This becomes even more tedious process if the influences of these factors need to be investigated. Moreover, several researchers have criticized the idea of predicting the behavior of UGMs in cyclic loading based on SFT tests, arguing that the behavior of UGMs is very complex and the structural response of the materials may not be the same in these two kinds of tests (Lekarp, 1999). To overcome these issues, Rahman and Erlingsson (2015) proposed a simpler model that relates the PD to the applied stresses and the number of load cycles. This model can be calibrated using a single RLT test and showed good performance. However, for field conditions and for application in a pavement design software, it is more convenient to use a model that relates the PD to the resilient strain instead of stress levels directly. In this regard, the Mechanistic-Empirical Pavement Design Guide (MEPDG) model, proposed by Tseng and Lytton (1989) has certain advantages. However, this model showed some limitations in performance when used for MS RLT tests of UGMs (Rahman and Erlingsson, 2014) and filed application (Fladvad \& Erlingsson, 2021). Hence, in this study, the Rahman and Erlingsson (2015) model was modified to include resilient strain as the input parameter instead of stress levels.

\section{PERMANENT DEFORMATION PROPERTIES OF UGMS}

UGMs are inhomogeneous and anisotropic in nature. Mechanical resistance of UGMs derive mainly from particle interlocking and friction between the particles (Lekarp, 1999). UGMs in pavements are subjected to cyclic stresses of varying magnitudes from the moving traffic load. These stress pulses contain vertical, horizontal and shear components. For UGMs, the vertical and horizontal stresses can only be compressive. Because of the moving wheel load, a rotation of the principal stress axes also occurs (Lekarp, 1999). The total deformation due to compressive cyclic stresses in a UGM consists of two parts: (a) elastic or recoverable or resilient deformation (RD) and (b) irreversible or plastic or permanent deformation (PD). Although small compared to the RD, the PD accumulates in the material for each load cycle and may become significantly large to cause failure of the pavement (Lekarp, 1999, Ramos et al., 2020).

The amount of PD is dependent on the magnitude of the stresses (Lekarp, 1999, Gidel et al., 2001). It is found to be directly related to deviator stress and inversely related to confining pressure. Several researchers have linked the amount of PD to some form of stress ratio consisting of both deviator stress and confining pressure. It has been also reported that reorientation of the principal stresses in pavement structures results in increased permanent deformations (Lekarp, 1999). Other factors governing the amount of permanent deformation in UGMs are stress history, moisture content, degree of compaction, PSD, aggregate type, etc. Permanent strain resulting from a certain stress level may be significantly reduced if the UGM had been subjected to another stress cycle previously (Brown and Hyde, 1975). 
Permanent deformation is generally reported to increase with increasing moisture where materials with higher fines content are more affected (Rahman and Erlingsson, 2013, Lekarp, 1999).

According to the shakedown range (SDR) theory, the evolution of PD with load applications can be classified into three types which are dependent on the stress level (Werkmeister et al., 2001). SDR A occurs for relatively low stress levels where the accumulation of PD ceases after a certain number of load cycles. For higher stress levels, SDR B occurs where the accumulation of PD continues at a steady rate. For even higher stress levels, SDR C behavior is observed where PD accumulates rapidly, leading to failure. Suggested criteria to distinguish between the different SDR behaviors can be found in Werkmeister (2003) and CEN (2004a).

Several models have been proposed for PD of UGMs (Ramos et al., 2020). One of the most referred to PD models is the one implemented in the Mechanistic Empirical Pavement Design Guide (MEPDG) (ARA, 2004), originally proposed by Tseng and Lytton (1989). This model implicitly considers the influence of the stress level, assuming a direct relationship between the resilient deformation and applied stresses and combines the influence of the number of load applications. This model is expressed as:

$$
\hat{\varepsilon}_{p}(N)=\varepsilon_{r} \varepsilon_{0} e^{-\left(\frac{\rho}{N}\right)^{\beta}}
$$

where, $\varepsilon_{0}, \rho$ and $\beta$ are material parameters and $\varepsilon_{r}$ is the resilient strain at $N^{\text {th }}$ load cycle. The parameter $\beta$ is estimated using the gravimetric moisture content, $w(\%)$ as:

$$
\log \beta=-0.61119-0.017638 w
$$

\section{EXPERIMENTAL PROCEDURE}

The model proposed in this article was developed based on MS RLT tests in the laboratory, conducted following the European standard EN-13286-7 (CEN, 2004a). The MS RLT test, in contrast to the single stage (SS) RLT test, applies several stress paths on a single specimen. This approach inherently demonstrates the effect of stress history and enables for a more comprehensive and realistic study of the material behavior. The sizes of the cylindrical specimens were $150 \mathrm{~mm}$ in diameter and $300 \mathrm{~mm}$ in height. The specimens were prepared using the vibro-compaction method. The axial deformations were measured using three linear variable displacement transducers (LVDTs), placed $120^{\circ}$ apart and anchored to the middle third of the specimen. Average readings from the LVDTs were used in the analyses. Haversine loading pulses with a frequency of $10 \mathrm{~Hz}$ and no rest period were applied. The tests were carried out under free drainage conditions. The confining pressure was applied using compressed air. The moisture contents reported in this study refer to the target or initial gravimetric moisture contents. The tests were replicated for better reliability and to account for the experimental dispersions usually encountered in RLT tests on UGMs. Here, the average measurements are reported.

For the MS loading approach, the European standard presents two sets of stress levels, termed as 'high stress level' (HSL) and 'low stress level' (LSL). Each set is divided into five sequences. Each of these sequences contains several stress paths with a constant confining pressure and different deviator stresses (total 28 stress paths for the HSL and 30 stress paths for the LSL). Each stress path is applied for 10,000 cycles. For the tests carried out here, the sequences were applied consecutively.

The MS RLT tests were conducted on eight different UGMs with different PSDs and a range of moisture contents. Some of the materials were tested applying both the HSL and LSL. One set of stress levels was used for fitting the model and the other set was used to validate the model by comparing the prediction obtained using the fitted model with the measured 
PD. Also, the influence of moisture on the model parameters was evaluated and used in the predictions.

One of the materials tested here was crushed rock aggregate obtained from Skärlunda in Sweden. Three different PSDs of this material were investigated, derived using the Fuller's equation with $n=0.62,0.45$ and 0.35 . Three other materials tested, referred to as Hallinden, VKB and SPV, were crushed rock aggregates obtained from different road construction sites in Sweden. The other two materials tested, referred to as SG1 and Siem 25, were natural aggregates dug out of gravel pits in Denmark where the fractions of crushed material were produced by crushing the oversized particles from the gravel pits. The PSDs of these materials are shown in Figure 1. The maximum particle size used for the tests was $31.5 \mathrm{~mm}$. The optimum moisture contents $\left(w_{\text {opt }}\right)$ and the maximum dry densities were determined using the modified Proctor method according to the European standard EN 13286-2 (CEN 2004b). Properties of these materials and the specific test conditions are summarized in Table 1.

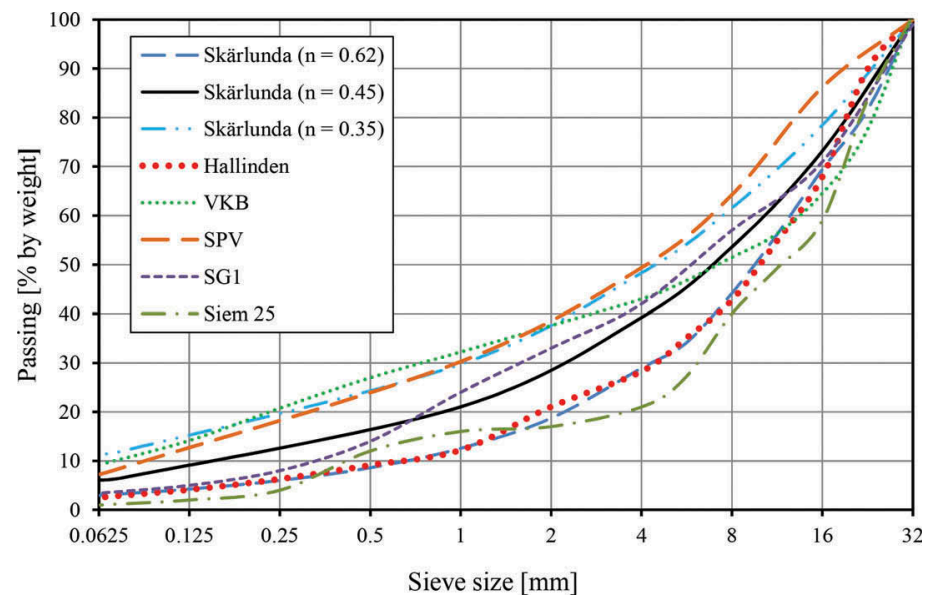

Figure 1. PSDs of the UGMs used for this study.

\section{THE PROPOSED MODEL}

In a previous study, the following regression based empirical model for the PD behavior of UGMs was proposed by the authors (Rahman and Erlingsson, 2015):

$$
\hat{\varepsilon}_{p}(N)=A N^{B S_{f}} S_{f}
$$

where $\hat{\varepsilon}_{p}(N)$ is the accumulated permanent strain after $N$ number of load cycles and $A$ and $B$ are regression parameters related to the material. The term $S_{f}$ describes the effect of stress condition on the development of PD which is expressed as:

$$
S_{f}=\frac{\left(\frac{q}{p_{a}}\right)}{\left(\frac{p}{p_{a}}\right)^{\alpha}}
$$

where, $q$ is the deviator stress, $p$ is the hydrostatic stress (one-third of the sum of the principal stresses) and $\alpha$ is a parameter determined using regression analysis. The term $p_{a}=100 \mathrm{kPa}$ 
(reference stress taken equal to the atmospheric pressure) was used to make the expression non-dimensional.

For a series of MS RLT tests with different UGMs with different moisture contents and degrees of compaction, the model showed reliable and satisfactory performance (Rahman and Erlingsson, 2015). However, for application of the model for field conditions using any layered elastic theory-based pavement analysis software, it becomes problematic if any of the calculated stresses turns out to be negative. For these kinds of applications, it is obvious that a resilient strain $\left(\varepsilon_{r}\right)$ based model would be more convenient and appropriate. Thus Equation (5) was modified by simply replacing $S_{f}$ with $\varepsilon_{r}$ as follows:

$$
\hat{\varepsilon}_{p}(N)=a N^{b \varepsilon_{r}} \varepsilon_{r}
$$

To use this model for MS RLT test conditions where several stress paths are consecutively applied to a single specimen, the time hardening approach (Erlingsson and Rahman, 2013) was adopted. According to this method, Equation (5) can be reconstructed for MS RLT tests as:

$$
\hat{\varepsilon}_{p_{i}}(N)=a\left(N-N_{i-1}+N_{i}^{e q}\right)^{b\left(\varepsilon_{r}\right)_{i}}\left(\varepsilon_{r}\right)_{i}
$$

where the suffix $i$ refers to the $i^{\text {th }}$ stress path, $\hat{\varepsilon}_{p_{i}}$ is the accumulated permanent strain at the end of $(i-1)^{\text {th }}$ stress path. $N_{i}^{e q}$ can be calculated as:

$$
N_{i}^{e q}=\left[\frac{\hat{\varepsilon}_{p_{i-1}}}{a\left(\varepsilon_{r}\right)_{i}}\right]^{b^{-1}\left(\varepsilon_{r}\right)_{i}^{-1}}
$$

\section{MODEL FITTING}

The model was fitted to the MS RLT test data using the least square curve fitting method. The initial values of the parameters were estimated based on boundary conditions and engineering judgement. For the parameter $a$, the initial value was set equal to the accumulated permanent strain times 1000 at the end of the first stress path and was restricted to be positive. The value of the parameter $b$ was restricted between 50 and 500 . The quality of fit achieved with the model was evaluated by the coefficient of determination $R^{2}$. Also, the correct matching of the SDR between modelled and measured data for each stress path was evaluated and expressed as percentage. For most of the cases, a value of $b$ close to 250 provided reasonably good fit. Thus, to avoid complications due to multiple possible combinations of parametric values, $b$ was fixed to 250 . Using this approach, reasonable qualities of fits were achieved by only optimizing the parameter $a$. Figure 2 shows an example of the measured versus modelled accumulated permanent strain as a function $N$ for one material with different moisture contents. The values of the parameters and the estimates of $R^{2}$ and SDR matching are presented in Table 1. Figure 2 and Table 1 show that the model fitted reasonably well with satisfactory values of $R^{2}$ and SDR matching. The missing data for some of the tests are because of termination of the tests due to excessive deformations.

The values of $a$ for the different specimens were plotted against $w$ in Figure 3. It shows that $a$ can be expressed as a linear function of $w$ (within the certain range used in this study) as follows:

$$
a=c_{1}(w)+c_{2}
$$

where, $c_{1}$ and $c_{2}$ are the regression parameters specific to each specimen. The values of these parameters for the different materials and the corresponding $R^{2}$ values are given in Table 5 . 


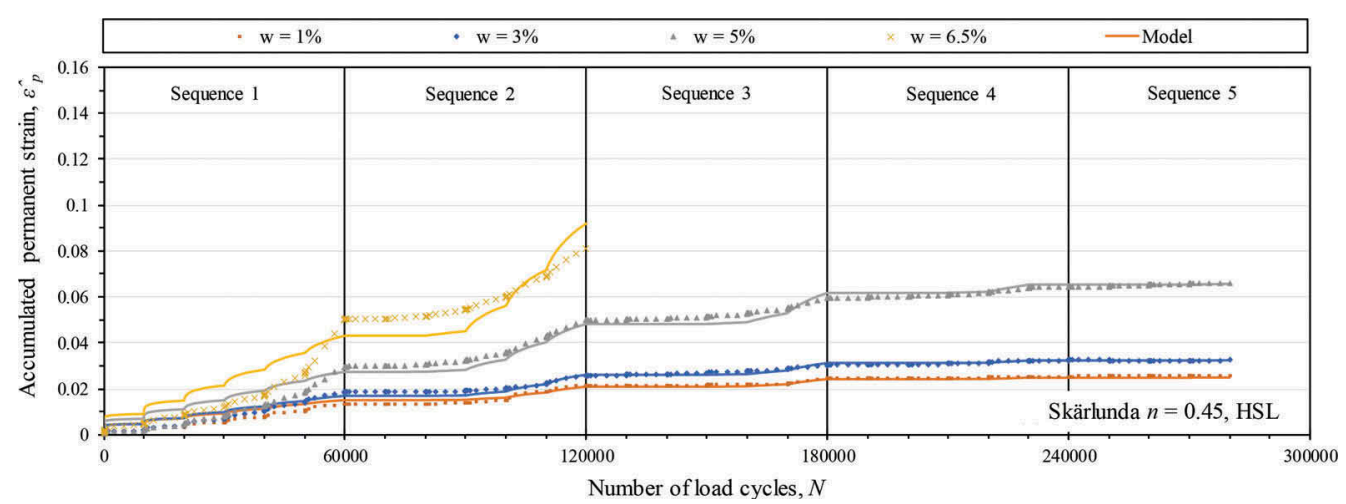

Figure 2. Measured and modelled accumulation of permanent strain for a series of $w$ (Skärlunda $n=0.45$, HSL).

Table 1. Material properties, test conditions and the calibrated model parameters.

\begin{tabular}{|c|c|c|c|c|c|c|c|c|c|}
\hline \multirow[b]{2}{*}{ Material } & \multirow[b]{2}{*}{$\begin{array}{l}\text { Specific } \\
\text { gravity } \\
{[-]}\end{array}$} & \multirow[b]{2}{*}{$\begin{array}{l}w_{o p t} \\
{[\%]}\end{array}$} & \multirow[b]{2}{*}{$\begin{array}{l}\text { Max. dry } \\
\text { density } \\
{\left[\text { ton } / \mathrm{m}^{3}\right]}\end{array}$} & \multicolumn{6}{|c|}{ Test condition } \\
\hline & & & & $w[\%]$ & $\begin{array}{l}\text { Dry } \\
\text { density } \\
{\left[\text { ton } / \mathrm{m}^{3}\right]}\end{array}$ & $\begin{array}{l}\text { Stress level } \\
\text { (used for } \\
\text { model } \\
\text { fitting) }\end{array}$ & $\begin{array}{l}\text { Parameter } \\
a \\
(b=250)\end{array}$ & $R^{2}$ & $\begin{array}{l}\text { SDR } \\
\text { matching } \\
{[\%]}\end{array}$ \\
\hline \multirow{4}{*}{$\begin{array}{l}\text { Skärlunda } \\
(n=0.62)\end{array}$} & \multirow[t]{4}{*}{2.64} & \multirow[t]{4}{*}{5.5} & \multirow[t]{4}{*}{2.11} & 1 & \multirow[t]{4}{*}{2.05} & HSL & 3.78 & 0.88 & 61 \\
\hline & & & & 3 & & HSL & 5.20 & 0.94 & 64 \\
\hline & & & & 5 & & HSL & 7.79 & 0.91 & 86 \\
\hline & & & & 7 & & HSL & 8.89 & 0.84 & 89 \\
\hline \multirow{4}{*}{$\begin{array}{l}\text { Skärlunda } \\
(n=0.45)\end{array}$} & \multirow[t]{4}{*}{2.64} & \multirow[t]{4}{*}{6} & \multirow[t]{4}{*}{2.26} & 1 & \multirow[t]{4}{*}{2.19} & HSL & 15.96 & 0.92 & 93 \\
\hline & & & & 3 & & HSL & 19.00 & 0.97 & 89 \\
\hline & & & & 5 & & HSL & 26.00 & 0.97 & 75 \\
\hline & & & & 6.5 & & HSL & 34.00 & 0.84 & 93 \\
\hline \multirow{5}{*}{$\begin{array}{l}\text { Skärlunda } \\
(n=0.35)\end{array}$} & \multirow[t]{5}{*}{2.64} & \multirow[t]{5}{*}{6.5} & \multirow[t]{5}{*}{2.22} & 1 & \multirow[t]{5}{*}{2.15} & HSL & 6.70 & 0.98 & 93 \\
\hline & & & & 2 & & HSL & 10.69 & 0.93 & 79 \\
\hline & & & & 3.5 & & HSL & 17.72 & -1.15 & 86 \\
\hline & & & & 5 & & HSL & 23.15 & 0.98 & 100 \\
\hline & & & & 6 & & HSL & 29.00 & 0.90 & 100 \\
\hline \multirow[t]{4}{*}{ Hallinden } & \multirow[t]{4}{*}{2.63} & \multirow[t]{4}{*}{5.5} & \multirow[t]{4}{*}{2.075} & 1 & \multirow[t]{4}{*}{2.01} & LSL & 2.55 & 0.99 & 89 \\
\hline & & & & 3.5 & & LSL & 2.62 & 0.93 & 89 \\
\hline & & & & 5.5 & & LSL & 2.76 & 0.99 & 93 \\
\hline & & & & 6.5 & & LSL & 3.10 & 0.98 & 71 \\
\hline \multirow[t]{3}{*}{ VKB } & \multirow[t]{3}{*}{2.54} & 6 & 2.21 & 2 & 2.19 & LSL & 4.19 & 0.73 & 68 \\
\hline & & & & 4.5 & & LSL & 4.66 & 0.95 & 82 \\
\hline & & & & 6 & & LSL & 9.73 & 0.90 & 82 \\
\hline SPV & 2.68 & 6.9 & 2.35 & 2 & 2.23 & LSL & 4.11 & 0.99 & 82 \\
\hline & & & & 4 & & LSL & 7.14 & 0.95 & 68 \\
\hline & & & & 7 & & LSL & 12.58 & 0.97 & 79 \\
\hline SG1 & 2.49 & 7.5 & 2.13 & 3.5 & 2.02 & HSL & 1.60 & 0.88 & 82 \\
\hline & & & & 5.5 & & HSL & 3.78 & 0.97 & 75 \\
\hline & & & & 7.5 & & HSL & 6.70 & 0.97 & 89 \\
\hline & & & & 8.5 & & HSL & 7.79 & 0.98 & 75 \\
\hline & & & & 9.2 & & HSL & 8.10 & 0.87 & 100 \\
\hline Siem 25 & 2.61 & 5 & 2.16 & 1 & 2.1 & LSL & 1.43 & 0.99 & 93 \\
\hline & & & & 3.5 & & LSL & 1.90 & 0.94 & 89 \\
\hline & & & & 5 & & LSL & 2.93 & 0.97 & 93 \\
\hline & & & & 7 & & LSL & 3.87 & 0.92 & 71 \\
\hline
\end{tabular}




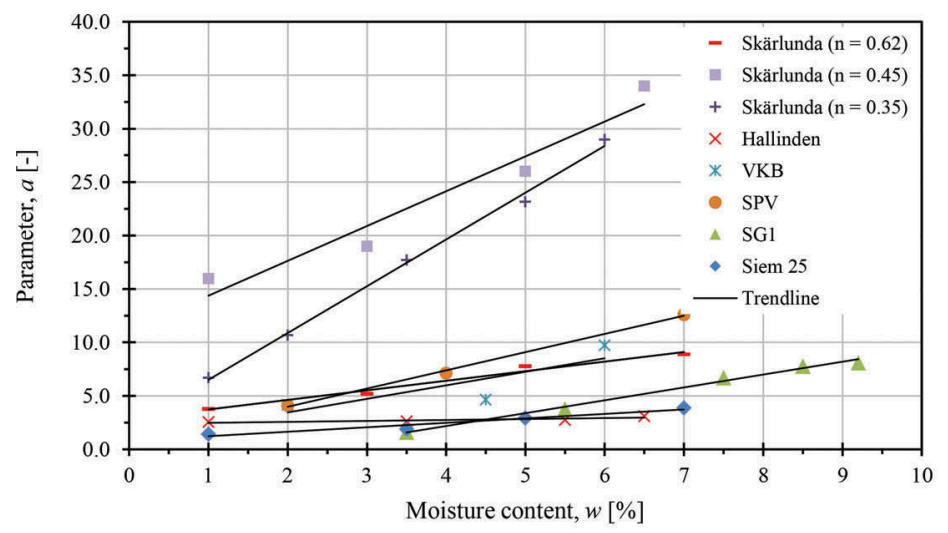

Figure 3. Parameter $a$ as a function of $w$ for the different materials.

Table 2. Parameters of Equation (8).

\begin{tabular}{llllllllll}
\hline Material & & $\begin{array}{l}\text { Skärlunda } \\
(n=0.62)\end{array}$ & $\begin{array}{l}\text { Skärlunda } \\
(n=0.45)\end{array}$ & $\begin{array}{l}\text { Skärlunda } \\
(n=0.35)\end{array}$ & Hallinden & VKB & SPV & SG1 & \multicolumn{2}{l}{$\begin{array}{l}\text { Siem } \\
25\end{array}$} \\
\hline Parameters & $c_{1}$ & 0.896 & 3.26 & 4.38 & 0.087 & 1.26 & 1.71 & 1.20 & 0.42 \\
& $c_{2}$ & 2.83 & 11.11 & 2.12 & 2.39 & 0.93 & 0.56 & -2.62 & 0.81 \\
$R^{2}$ & & 0.98 & 0.94 & 0.99 & 0.76 & 0.69 & 0.99 & 0.99 & 0.94 \\
\hline
\end{tabular}

\section{PREDICTING PD USING THE FITTED MODELS}

For validation, the fitted models for the different UGMs in section 5 were used to predict the accumulation of PD in different combination of stress levels other than those used for the fittings. Thus, if HSL was used for the fitting, LSL was used for the validation and vice versa. The predicted PD were then compared to the actual measurements from the MS RLT tests. The quality of predictions was evaluated using the $R^{2}$ values and SDR matching. For comparison, the MEPDG model was used in the same manner. Additionally, the parameter $a$ was calculated for the specific moisture contents using Equation 8 and Table 2 and used in the model during validation which is represented here as 'proposed model (moisture based)'. An example of the test data and the predictions by the models are shown in Figure 4 . The $R^{2}$ values and SDR matching for the models are presented in Table 3. These indicate that all models worked reasonably well for predicting the PD of these UGMs in MS RLT tests. However, the proposed model showed better agreement with the measurements, especially during the last two stress paths (sequence 5) for all cases. The moisture-based version of the model also worked well. Thus, it indicates that using this approach, the model may be used reliably to predict the PD behavior of UGMs with variations in stress level and moisture content.

\section{APPLICATION OF THE MODEL FOR FIELD CONDITIONS}

Besides for the RLT test environment, the model was employed to capture the PD behavior of UGMs in a real pavement structure. For this, data from an accelerated pavement testing (APT) of an instrumented pavement test section were used. The APT was conducted in a controlled environment using a heavy vehicle simulator (HVS). The schematic of the test section and instrumentations is shown in Figure 5 (a). During the test, the groundwater table (GWT) was raised after 48,6750 load cycles (converted to equivalent standard axle loads (ESALs)), which is shown in this figure. Details of the structure and the test can be found in Saevarsdottir and 


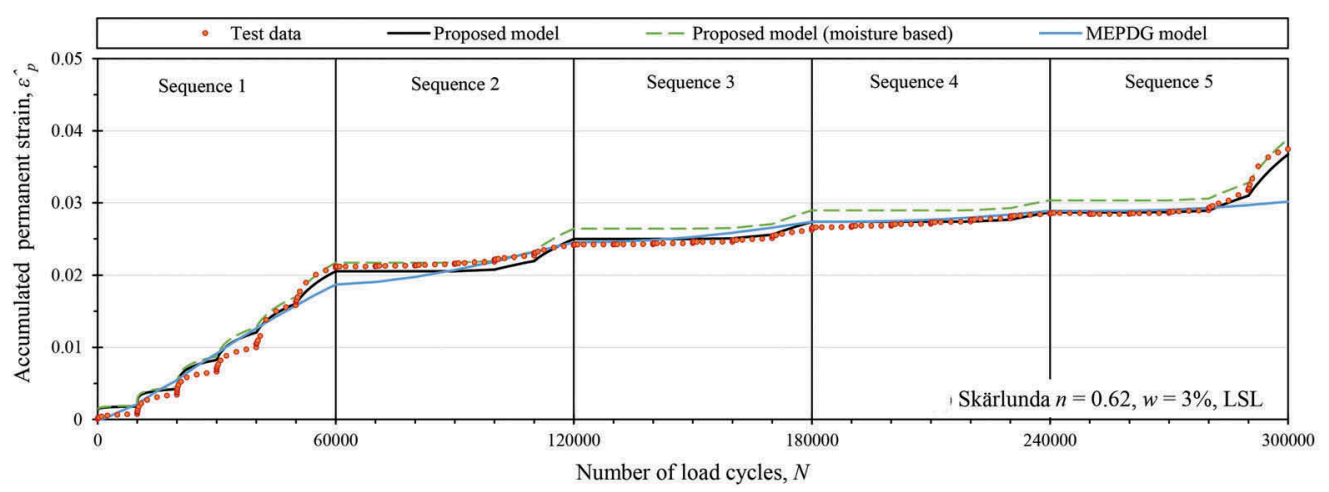

Figure 4. Measured versus predicted accumulation of permanent strain using the fitted models (Skärlunda $n=0.62$, LSL).

Table 3. Statistical evaluation of the qualities of predictions by the models.

\begin{tabular}{|c|c|c|c|c|c|c|c|c|}
\hline \multirow[b]{2}{*}{ Material } & \multirow[b]{2}{*}{$\begin{array}{c}\mathrm{w} \\
{[\%]}\end{array}$} & \multirow[b]{2}{*}{$\begin{array}{c}\text { Stress } \\
\text { level } \\
\text { (used for } \\
\text { validation) }\end{array}$} & \multicolumn{3}{|l|}{$R^{2}$} & \multicolumn{3}{|c|}{ SDR matching [\%] } \\
\hline & & & $\begin{array}{l}\text { Proposed } \\
\text { model }\end{array}$ & $\begin{array}{l}\text { Proposed } \\
\text { model } \\
\text { (moisture } \\
\text { based) }\end{array}$ & $\begin{array}{l}\text { MEPDG } \\
\text { model }\end{array}$ & $\begin{array}{l}\text { Proposed } \\
\text { model }\end{array}$ & $\begin{array}{l}\text { Proposed } \\
\text { model } \\
\text { (moisture } \\
\text { based) }\end{array}$ & $\begin{array}{l}\text { MEPDG } \\
\text { model }\end{array}$ \\
\hline $\begin{array}{l}\text { Skärlunda } \\
n=0.35\end{array}$ & 1 & LSL & 0.98 & 0.97 & 0.89 & 96 & 96 & 64 \\
\hline $\begin{array}{l}\text { Skärlunda } \\
n=0.62\end{array}$ & 3 & LSL & 0.98 & 0.96 & 0.97 & 82 & 82 & 61 \\
\hline SG1 & 5.5 & LSL & 0.98 & 0.96 & 0.96 & 100 & 100 & 79 \\
\hline
\end{tabular}

Erlingsson (2015). The required resilient strain $\left(\varepsilon_{r}\right)$ values as inputs for calibrating the model and the actual accumulated PD of the different layers were obtained from the readings of the instrumentations. The parameters of the model were adjusted to match the measured data with the predictions. In this case, the values of the parameter $a$ close to those for the RLT tests worked well. Like the RLT tests, the values of the parameter $b$ as 250 worked here too except for the base layer where a value of 60 provided the best fit. The values of $a$ were different for the moist and wet conditions (i.e. before and after raising the GWT, respectively) for the base and subgrade. The measured and modelled accumulated PD of the different layers of the test structure are shown in Figure 5(b). The values of the model parameters are presented in Table 4. Generally, good agreements between the measured and modelled responses were observed. The ranges of the model parameters were stable as well indicating reliability of the model.

\section{CONCLUSIONS}

In this study, a model to predict the accumulation of PD in UGMs with the number of load applications for variable stress conditions was derived. The objective was to better suit a preexisting model for field applications and to implement it in a pavement analysis software in future. The study was based on MS RLT tests since it allows for a comprehensive study of the material behavior with minimal effort. The idea was to develop a simple and reliable model for MS loading conditions that can be calibrated with reduced effort compared to some of the existing models. 
(a)

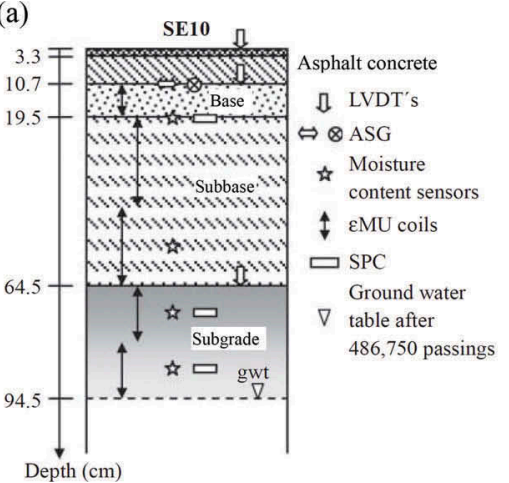

(b)

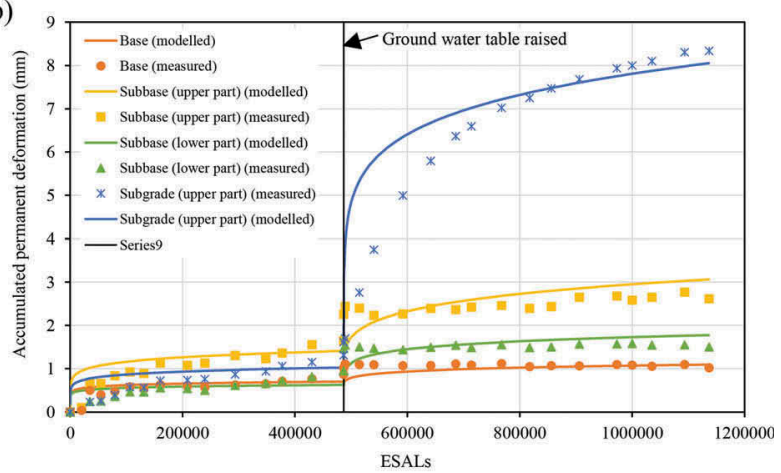

Figure 5. (a) Schematic of the test structure (Saevarsdottir and Erlingsson, 2015). (b) Measured vs. modelled PD in different layers.

Table 4. Model parameters for the different layers of the pavement section.

\begin{tabular}{llllr}
\hline & \multicolumn{2}{l}{ Model parameters } & & Wet \\
\cline { 2 - 5 } & Moist & & $\mathrm{b}$ & $\mathrm{b}$ \\
\cline { 2 - 5 } Layer & $\mathrm{a}$ & 60 & 2.5 & 60 \\
\hline Base & 2.2 & 250 & 2.5 & 250 \\
Subbase (upper part) & 2.5 & 250 & 4 & 250 \\
Subbase (lower part) & 4 & 250 & 9.5 & 250 \\
Subgrade (upper part) & 2 & & $\mathrm{~b}$ & \\
\hline
\end{tabular}

The model proposed here can be calibrated for a specific material using a single RLT test without conducting SFT tests. The model was validated using MS RLT test data applying the time hardening approach. Despite its simplicity, the proposed model showed reliable results. Some deviances in predictions compared to measured values for some cases may be considered acceptable if one allows for the experimental scatter usually encountered in MS RLT tests with UGMs. In this study, for simplicity, the parameters $b$ was restricted to 250 leaving only parameter $a$ to be regressed for different UGM specimens. Yet, the model provided good quality of fit. With this approach, it was possible to investigate the impact of moisture on parameter $a$. The model was also successfully used for an in-situ pavement condition in HVS testing. With additional MS RLT testing of several other UGMs (not presented here), the observed ranges of the parameters $a$ and $b$ are presented in Table 5.

Table 5. Suggested range of model parameters.

\begin{tabular}{llll}
\hline Parameter & $\begin{array}{l}\text { Well-graded } \\
(w=1 \%-7 \%)\end{array}$ & $\begin{array}{l}\text { Fine graded } \\
(w=1 \%-10 \%)\end{array}$ & $\begin{array}{l}\text { Coarse and open graded } \\
(w=1 \%-7 \%)\end{array}$ \\
\hline$a$ & $1-15$ & $1-30$ & $1-10$ \\
$b$ & $100-250$ & $200-350$ & $150-250$ \\
\hline
\end{tabular}

*Degree of compaction: 95-97\% (modified Proctor method) 
Since this was a limited study, the model developed here should be validated with more tests with a wider range of materials and different field conditions. With additional studies, it will be possible to incorporate the influence of moisture, PSD and degree of compaction into the model and establish reasonable ranges of the parameters. Further work is currently underway to validate and implement this model for real pavement conditions and in a pavement analysis software.

\section{ACKNOWLEDGEMENTS}

This work was sponsored by the Swedish Transport Administration (Trafikverket). The Danish aggregates were provided by the Danish Road Directorate.

\section{REFERENCES}

ARA, Inc., 2004. Guide for the Mechanistic Empirical Design of New and Rehabilitated Pavement Structures. Final report, NCHRP1-37A, Transportation Research Board, National Research Council, Washington D.C., USA.

Brown, S. F. and Hyde, A. F. L., 1975. Significance of cyclic confining stress in repeated-load triaxial testing of granular material. Transportation Research Record: Journal of the Transportation Research Board, Transportation Research Board of the National Academies, Washington, D.C., No. 537, 4958 .

CEN-European Committee for Standardization, 2004a. Cyclic Load Triaxial Test for Unbound Mixtures. Brussels: European Standard, EN 13286-7.

CEN-European Committee for Standardization, 2004b. Test Methods for the Determination of the Laboratory Reference Density and Water Content - Proctor Compaction. Brussels: European Standard, EN 13286-2.

Di Graziano, A., Marchetta, V. and Cafiso, S., 2020. Structural health monitoring of asphalt pavements using smart sensor networks: A comprehensive review. Journal of Traffic and Transportation Engineering (English Edition), 7(5), pp. 639-651.

Erlingsson, S. and Rahman, M. S., 2013. Evaluation of Permanent Deformation Characteristics of Unbound Granular Materials by Means of Multistage Repeated-Load Triaxial Tests. Transportation Research Record: Journal of the Transportation Research Board, Transportation Research Board of the National Academies, Washington, D.C., No. 2369, 11-19. DOI: 10.3141/2369-02.

Fladvad, M. and Erlingsson, S., 2021. Modelling the response of large-size subbase materials tested under varying moisture conditions in a heavy vehicle simulator, Road Materials and Pavement Design, DOI: 10.1080/14680629.2021.1883462.

Gidel, G., et al., 2001. A New Approach for Investigating the Permanent Deformation Behaviour of Unbound Granular Material Using the Repeated Load Triaxial Apparatus. Bulletin de Liaison des Laboratoires des Ponts et Chaussées, No. 233, July-August, 2001, 5-21.

Hornych, P. and El Abd, A., 2004. Selection and Evaluation of Models for Prediction of Permanent Deformations of Unbound Granular Materials in Road Pavements. Competitive and Sustainable Growth (GROWTH) Programme, SAM-05-DE10.

Korkiala-Tanttu, L., 2005. A New Material Model for Permanent Deformations in Pavements. In: Proceedings of the 7th International Conference on Bearing Capacity of Roads and Airfields, BCRRA ' 05 , Trondheim, Norway.

Lekarp, F., 1999. Resilient and Permanent Deformation Behavior of Unbound Aggregates under Repeated Loading. Doctoral thesis. Royal Institute of Technology (KTH), Stockholm, Sweden.

Rahman, M. S. and Erlingsson, S., 2013. Moisture Sensitivity of the Deformation Properties of Unbound Granular Materials, Proceedings of the 9th International Conference on Bearing Capacity of Roads and Airfields, BCRRA '13, Trondheim, Norway, pp. 777-786.

Rahman, M.S. and Erlingsson, S., 2014. Predicting permanent deformation behaviour of unbound granular materials, International Journal of Pavement Engineering, 16:7, 587-601, DOI: 10.1080/ 10298436.2014.943209.

Rahman, M.S. and Erlingsson, S., 2015. A model for predicting permanent deformation of unbound granular materials, Road Materials and Pavement Design, 16:3, 653-673, DOI: 10.1080/ 14680629.2015.1026382.

Ramos, A., Gomes Correia, A., Indraratna, B., Ngo, T., Calçada, R. and Costa, P. A., 2020. Mechanistic-empirical permanent deformation models: Laboratory testing, modelling and ranking, Transportation Geotechnics, 23, art. no. 100326. 
Saevarsdottir, T. and Erlingsson, S., 2015 Modelling of responses and rutting profile of a flexible pavement structure in a heavy vehicle simulator test, Road Materials and Pavement Design, 16:1, 1-18, DOI: 10.1080/14680629.2014.939698.

Tseng, K.H. and Lytton, R.L., 1989. Prediction of permanent deformation in flexible pavement materials. Implication of Aggregates in Design, Construction, and Performance of Flexible Pavements, ASTM STP 1016, H. G. Schrauders, and C. R. Marek, eds. American Society for Testing and Materials, Philadelphia, pp. 154-172.

Werkmeister, S., 2003. Permanent Deformation Behavior of Unbound Granular Materials. Thesis (PhD). University of Technology, Dresden, Germany.

Werkmeister, S., Dawson, A. R. and Wellner, F., 2001. Permanent Deformation Behavior of Granular Materials and the Shakedown Concept. Transport Research Record, Journal of the Transportation Research Board (TRB), No. 1757, 75-81. 